\title{
ARBORIZAÇÃO URBANA COM NIM INDIANO NA CIDADE DE SANTARÉM, PARÁ, BRASIL
}

\author{
URBAN ARBORIZATION WITH INDIAN NEEM IN SANTARÉM, PARÁ, BRAZIL \\ Rrobhnny Cemagui de Oliveira Dantas ${ }^{1}$, Talita Godinho Bezerra², Thiago Almeida Vieira ${ }^{3}$
}

\section{RESUMO}

Avaliou-se o uso do nim indiano (Azadirachta indica A. Juss.) na arborização urbana de Santarém, Pará. Foi realizado um levantamento de todas as árvores com diâmetro à altura do peito (DAP) $\geq 10 \mathrm{~cm}$ na área central do município, abrangendo sete bairros. Foram mensuradas: altura total $(\mathrm{Ht})$, altura da $1^{\circ}$ ramificação $(\mathrm{Hr})$, diâmetro do caule, diâmetro da copa (DC) (sentidos N-S e E-W), estado geral do indivíduo, condições de fitossanidade, local de ataque, injúrias, pavimento, afloramento de raiz e ação recomendada. Avaliou-se que na região central cidade de Santarém, a maioria dos indivíduos de nim apresenta porte médio (65\%) com altura até $4,8 \mathrm{~m}$. Identificou-se que $55 \%$ dos indivíduos encontram-se em ótimo estado, com bom desenvolvimento da copa, sem lesões graves ou interferências antrópicas significativas.

Palavras-chave: Amazônia; Azadirachta indica; Paisagismo.

\begin{abstract}
An evaluation of the use of indian neem (Azadirachta indica A. Juss.), in the urban afforestation of the municipality of Santarém, Pará was realized. A survey of all trees with diameter at chest height (DBH) $\geq$ $10 \mathrm{~cm}$ was carried out in the central area of the municipality, covering seven neighborhoods. The variables measured were: total height $(\mathrm{Ht})$, height of $1 \mathrm{st}$ branch $(\mathrm{Hr})$, stem diameter, crown diameter (DC) (senses NS and EW), general state of the individual, plant health conditions, place of attack, injuries, pavement, root outcrop and recommended action. It was assessed that in the central region of Santarém, the majority of neem individuals presented medium size $(65 \%)$ with height up to $4.8 \mathrm{~m}$. It was identified that $55 \%$ of the individuals are in good condition, with good development of the crown, without serious injuries or anthropic interferences.
\end{abstract}

Keywords: Amazon; Azadirachta indica; Landscaping.

Recebido em 05.03.2018 e aceito em 18.05.2018

1 Engenheiro Florestal. Graduado pela Universidade Federal do Oeste do Pará. Santarém/PA. Email: rrobhnnyd@gmail.com

2 Engenheira Florestal. Mestranda em Ciências Florestais. Universidade Federal rural da Amazônia. Belém/PA. Email: talita.gbezerra@gmail.com

3 Engenheiro Florestal. Doutor em Ciências Agrárias. Professor da Universidade Federal do Oeste do Pará. Santarém/PA. Email: thiago.vieira@ufopa.edu.br 


\section{INTRODUÇÃO}

As cidades foram crescendo, na maioria das vezes, de forma muito rápida e desordenada, sem planejamento adequado de ocupação, provocando vários problemas que interferem na qualidade de vida das pessoas (PIVETTA; SILVA FILHO, 2002).

A exemplo, cita-se o pouco uso de árvores ao longo dos logradouros. As árvores exercem um papel fundamental para a comodidade do meio urbano, demandando uma crescente necessidade por áreas verdes urbanas a serem manejadas como um recurso de múltiplo uso em prol de toda a sociedade (FILIK; SILVA; LIMA, 2007).

A arborização urbana refere-se ao uso de vegetação, predominantemente arbórea, presente em uma cidade, cultivada em áreas particulares (jardins e quintais) e públicas, tais como praças, parques e vias públicas (CABRAL, 2013). Contudo, é indispensável um planejamento preliminar, envolvendo práticas de manejo e gerenciamento integrado, com a finalidade de alcançar melhorias para a cidade e a população (CRISPIM et al., 2014).

Uma das espécies que tem sido utilizada na arborização urbana é a Azadirachta indica A. Juss (nim indiano), espécie exótica introduzida no Brasil. De acordo com Moreira et al. (2012), esta espécie tem despertado a atenção e seus produtos têm sido cada vez mais utilizados na área de produção vegetal. Em sua área de ocorrência natural, esta espécie é conhecida especialmente por suas propriedades medicinais e inseticidas, bem como pela resistência e a dureza da sua madeira (RODRIGUES et al., 2017).

O extrato e óleo obtidos a partir de plantas de nim indiano foi sugerido como um controle alternativo de pragas, isto porque apresentam qualidade de serem seletivos, biodegradáveis e têm poucos efeitos sobre o organismo não alvo (BOTTI et al., 2015). A azaractina, principal composto ativo da espécie, tem baixa persistência no ambiente por ter rápida degradação pela luz solar (BOURSIER et al., 2011).

No Brasil, o nim indiano tem sido cultivado em regiões dos biomas Cerrado, Caatinga, Mata Atlântica e Amazônia (NEVES et al., 2013). O uso do nim foi relatado em sistemas agroflorestais (VIEIRA et al., 2007) e em sistema silviculturais, em consórcio com mogno (Swietenia macrophylla King) (SILVA; ROSA; VIEIRA, 2013).

$\mathrm{Na}$ arborização urbana, o nim indiano é utilizado no paisagismo de casas e edifícios, bem como em ruas, avenidas e praças (SOTO; DIAZ; RAMIREZ, 2014), suportando muito bem podas constantes, inclusive podas drásticas (LUNDGREN; SILVA; ALMEIDA, 2013).

Diante disso, o objetivo deste trabalho foi avaliar de forma quantitativa e qualitativa os indivíduos de nim indiano (Azadirachta indica) na arborização urbana da cidade de Santarém, Pará. 


\section{MATERIAL E MÉTODOS}

\section{Caracterização da Área de Estudo}

O estudo foi realizado no município de Santarém, localizado na região oeste do Pará, na confluência dos rios Amazonas e Tapajós, entre as coordenadas $02^{\circ} 25^{\prime} 30^{\prime \prime}$ Sul e $54^{\circ} 42^{\prime}$ 50" Oeste, com altitude média de 36 metros e uma população estimada em 299.419 habitantes e ocupa uma área de $22.887,08 \mathrm{~km}^{2}$, sendo que $77 \mathrm{~km}^{2}$ estão em perímetro urbano (IBGE, 2012).

Segundo a classificação climática de Köppen, Santarém enquadra-se no tipo climático Am, com clima equatorial úmido e uma estação seca bem definida e outra com elevados índices pluviométricos. O clima dominante na região é quente e úmido, com temperatura média anual variando entre $25^{\circ}$ e $28^{\circ} \mathrm{C}$.

\section{Coleta de Dados}

Os dados foram coletados na área central do município de Santarém, Pará, abrangendo sete bairros (Aldeia, Aparecida, Caranazal, Centro, Fátima, Laguinho e Santa Clara), optando-se pelo levantamento total dos indivíduos de nim indiano em todas as ruas da região delimitada (Figura 1). O critério de inclusão foi de árvores com diâmetro à altura do peito $(\mathrm{DAP}) \geq 10 \mathrm{~cm}$.

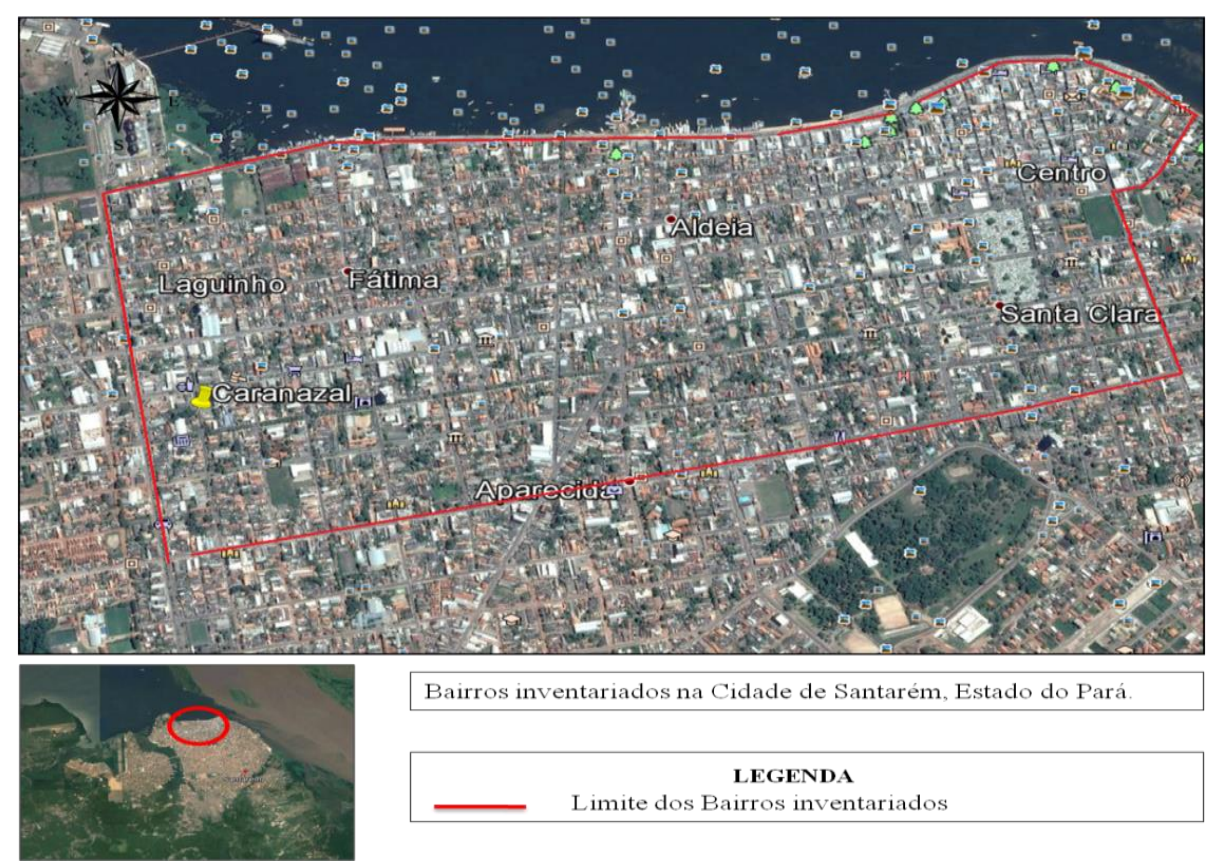

Fonte: Google Earth (2017)

Figura 1. Localização da área de estudo, Santarém, Pará.

Figure 1. Localization of study area, Santarém, Pará. 
Os dados foram coletados nos meses de janeiro a março de 2016. Para isso, adaptouse uma ficha de preenchimento da metodologia proposta por Pivetta e Silva Filho (2002), identificando as seguintes variáveis: altura total $(\mathrm{Ht})$, altura da 1ำ ramificação $(\mathrm{Hr})$, diâmetro do caule, diâmetro da copa (DC) (sentidos N-S e E-W), estado geral do indivíduo, condições de fitossanidade, local de ataque, injúrias, pavimento, afloramento de raiz e ação recomendada.

\section{Análise de dados}

Os dados foram analisados de forma quantitativa e qualitativa por meio da estatística descritiva. Para análise dos dados foi utilizado o programa Microsoft Exce ${ }^{\circledR}$ for Windows versão 2013, a partir da compilação, processamento e representação gráfica dos dados.

\section{RESULTADOS E DISCUSSÃO}

Neste estudo, foram identificados 49 indivíduos de nim indiano. De 25 logradouros analisados na área avaliada, 14 continham a presença da espécie, ao passo que cinco deles (travessas e avenidas) concentraram cerca 53\% dos indivíduos (Figura 2).

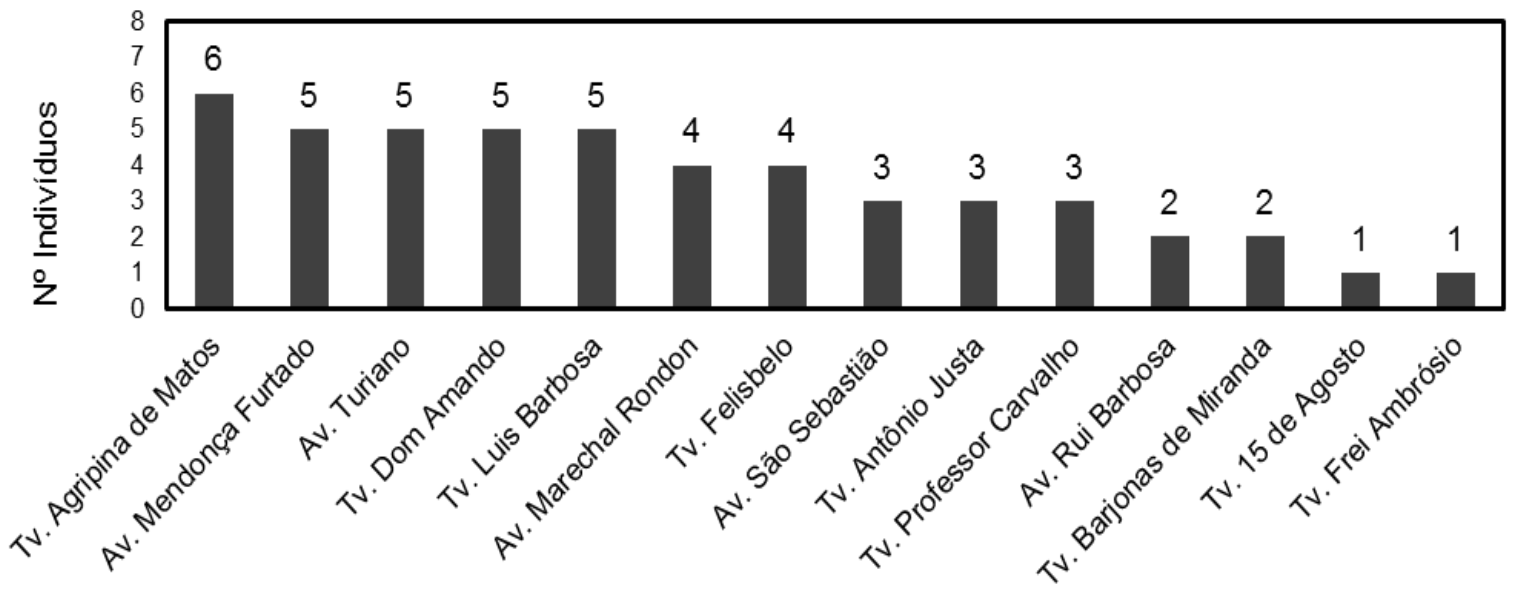

Figura 2. Distribuição de indivíduos de Azadirachta indica presentes na arborização de Santarém, Pará. Figure 2. Distribution of Azadirachta indica individuals, present in afforestation of Santarém, Pará.

No bairro "Laguinho" encontrou-se a maior frequência de indivíduos (13), seguido do "Centro" (9), posteriormente o bairro de "Fátima" (8). No bairro "Liberdade" verificou-se a menor quantidade de indivíduos (2) (Figura 3). 


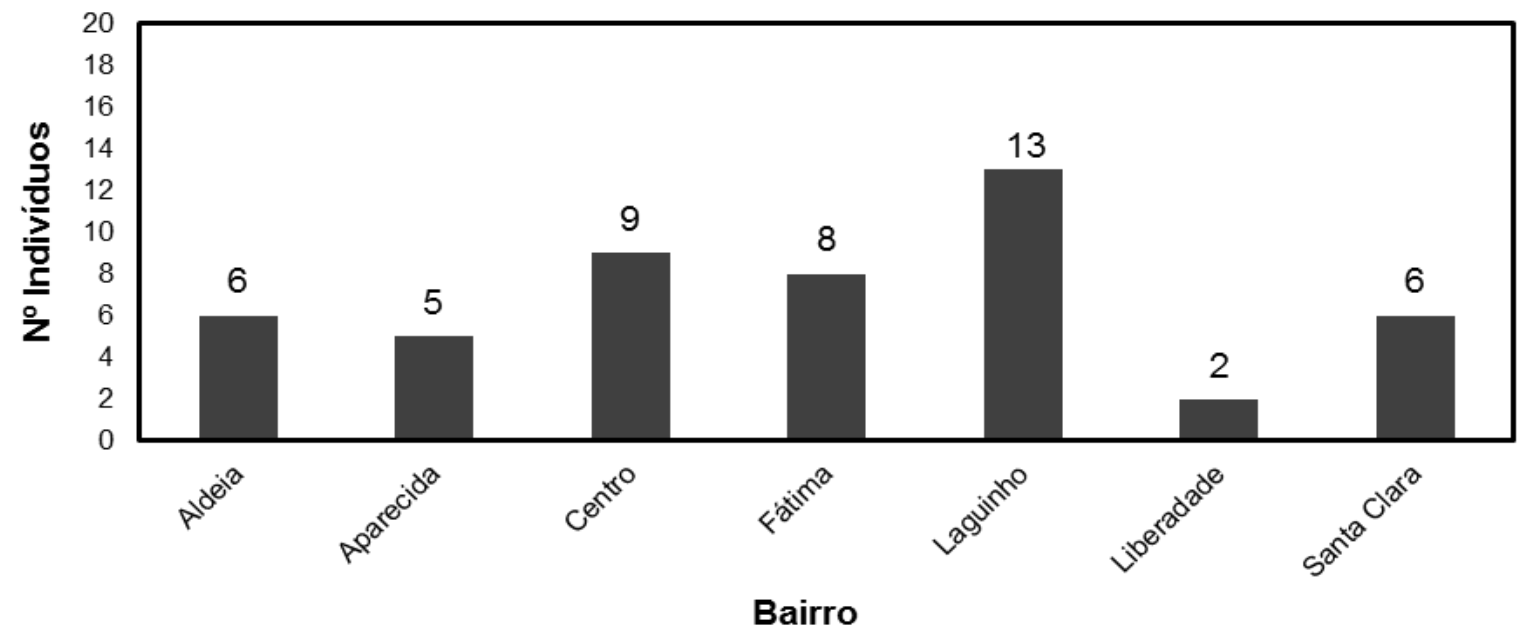

Figura 3. Distribuição de indivíduos de Azadirachta indica, por bairro na região central de Santarém, Pará.

Figure 3. Distribution of Azadirachta indica individuals by neighborhood in the central region of Santarém, Pará.

O uso de espécies exóticas na arborização urbana tem sido uma prática comum (LIMA e SILVA JÚNIOR, 2010; SAMPAIO et al., 2011; SOUZA, DODONOV; CORTEZ, 2012). Em estudo realizado por Fabricante et al. (2017), no Campus de Ciências Agrárias da Universidade Federal da Paraíba, da cidade de Areia (PB), foi constatada a presença de 76 espécies vegetais, dentre elas 26 exóticas, e destas o nim indiano foi uma das três principais espécies identificadas na arborização daquela área.

Sampaio et al. (2011), analisando a composição florística da arborização das vias públicas de bairros de Campo Mourão (PR), destacam que nem toda espécie exótica traz necessariamente prejuízos ambientais e/ou sociais.

Por outro lado, Lima e Silva Júnior (2010) alertam que a má adaptação da espécie exótica pode levar a problemas estruturais nos logradouros. Neste sentido, Santos, Antunes e Bessegatto (2017) sugerem a substituição gradativa das espécies exóticas por nativas, o que proporcionaria benefícios à biodiversidade e ecossistemas locais, dentre os quais, conforme apontam Souza, Dodonov e Cortez (2012), a conservação de espécies nativas fora de seus locais de origem.

Na Figura 4, observa-se que a distribuição das árvores de $A$. indica concentrou-se em sua maioria nas menores classes de diâmetro. Este resultado pode indicar que se trata de jovens indivíduos. Contudo, Souza, Dodonov e Cortez (2012), alertam que a prática de poda pode descaracterizar o crescimento normal de uma dada espécie, o que levaria indivíduos maduros terem porte de jovens. 


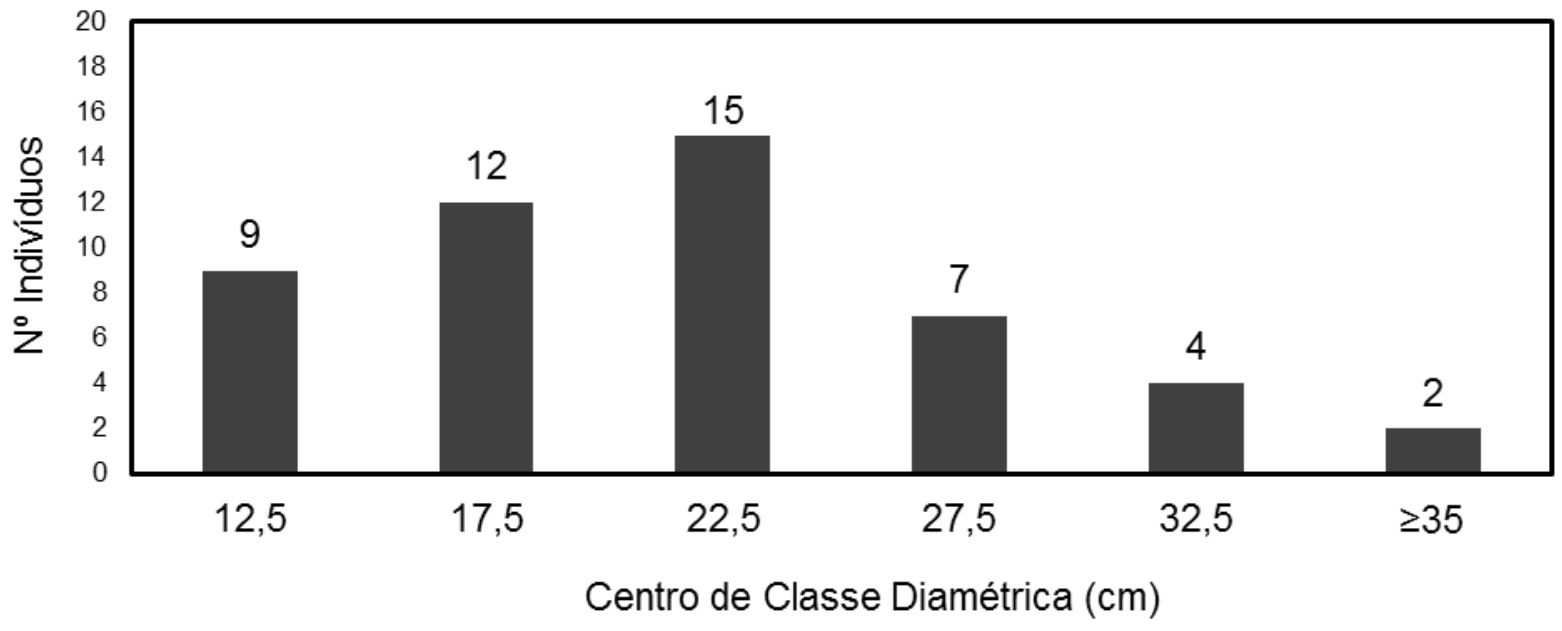

Figura 4. Distribuição de indivíduos arbóreos de Azadirachta indica por classe diamétrica, localizados na região central da cidade de Santarém, Pará.

Figure 4. Distribution of Azadirachta indica arboreal individuals by diametric class, in the central region of Santarém, Pará.

Em relação ao Diâmetro da Copa, como pode ser visto na Figura 5, a classe de tamanho II $(4 \leq \mathrm{DC}<6 \mathrm{~m})$ e III $(6 \leq \mathrm{DC}<8 \mathrm{~m})$ agruparam $46,94 \%$ e $22,45 \%$ do total de indivíduos levantados, respectivamente.

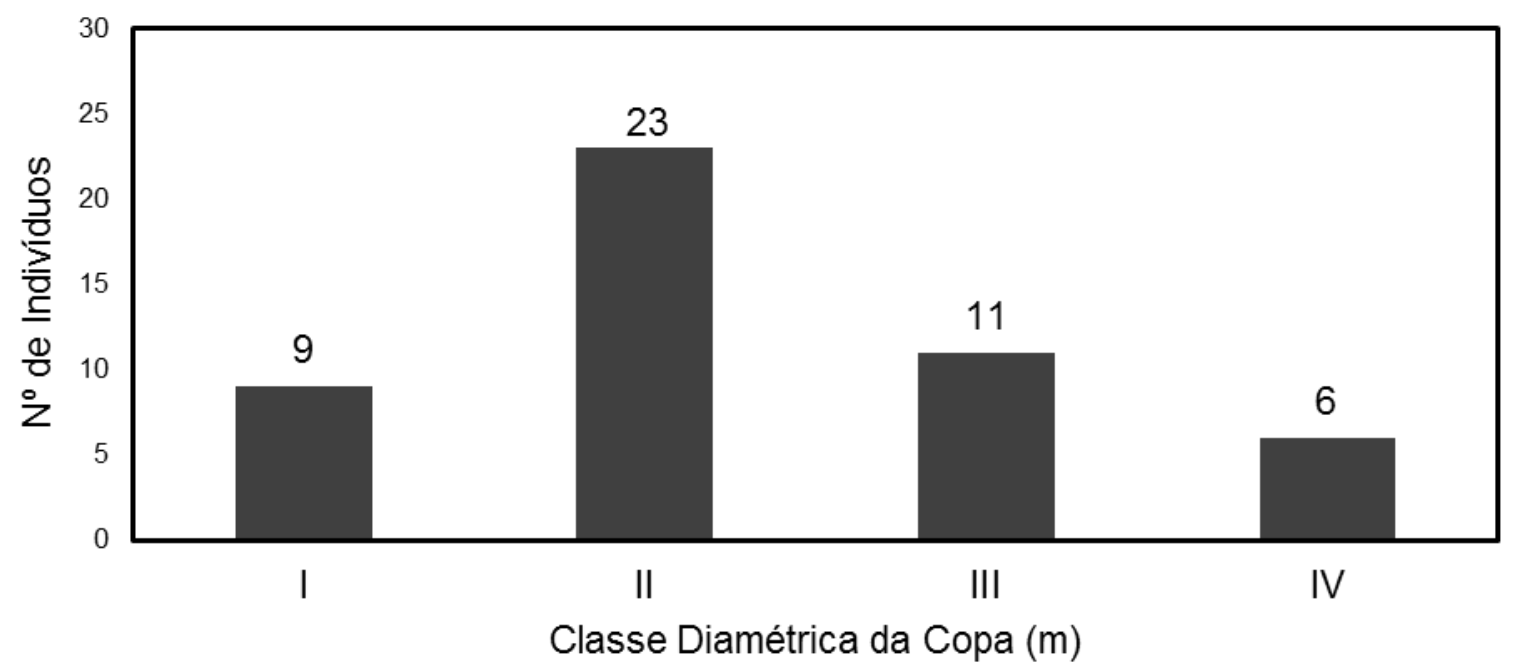

Figura 5. Distribuição dos indivíduos de Azadirachta indica por classe diamétrica de copa, Santarém, Pará. Sendo: I $(2 \leq \mathrm{DC}<4 \mathrm{~m})$, II $(4 \leq \mathrm{DC}<6 \mathrm{~m})$, III $(6 \leq \mathrm{DC}<8 \mathrm{~m})$ e IV $(\mathrm{DC} \geq 8 \mathrm{~m})$.

Figure 5. Distribution of Azadirachta indica individuals by diametric class of canopy, Santarém, Pará. Being: I $(2 \leq \mathrm{DC}<4 \mathrm{~m})$, II $(4 \leq \mathrm{DC}<6 \mathrm{~m})$, III $(6 \leq \mathrm{DC}<8 \mathrm{~m})$ and IV $(\mathrm{DC} \geq 8 \mathrm{~m})$.

O porte das espécies arbóreas é uma variável de grande importância para a arborização urbana. Na região central cidade de Santarém, a maioria dos indivíduos de nim indiano apresentou porte médio (65\%) com altura até $4,8 \mathrm{~m}$, o que permite inferir que esses indivíduos foram implantados há pouco tempo (Figura 6). 


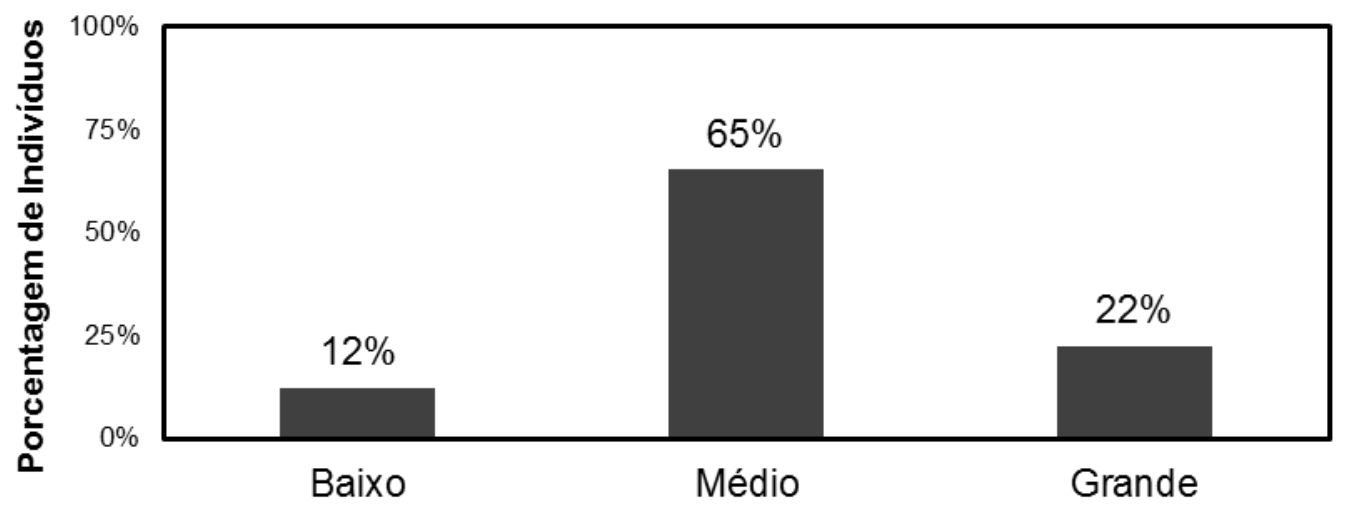

Porte dos indivíduos levantados

Figura 6. Porte dos indivíduos de Azadirachta indica levantados na região central da cidade de Santarém, Pará. Nota: Baixo $(4,8 \leq \mathrm{Ht})$; Médio $(4,8 \leq \mathrm{DC}<8,8 \mathrm{~m})$; e Grande $(\mathrm{Ht} \geq 8,8 \mathrm{~m})$.

Figure 6. Size of Azadirachta indica individuals in the central region of Santarém, Pará. Note: Low (4.8 $\leq$ $\mathrm{Ht})$; Medium $(4.8 \leq \mathrm{DC}<8.8 \mathrm{~m})$; and High $(\mathrm{Ht} \geq 8.8 \mathrm{~m})$.

Os indivíduos de porte baixo tiveram frequência de $12 \%$, já os de grande porte representam $22 \%$ dos indivíduos levantados. A poda realizada em alguns do indivíduos inventariados pode ser um indicativo do reduzido número de indivíduos concentrados na classe de porte grande. A poda é um importante trato cultural a ser realizado em plantas arbóreas utilizadas na arborização urbana. Neste sentido, Almeida e Rondon Neto (2010a) alertam que a ocorrência de desgalhamento da árvore desde a base, ou próximo dela, quando plantadas em calçadas pode dificultar a transição de pedestres.

O porte dos indivíduos é uma característica que deve ser utilizada para o adequado planejamento da arborização urbana. De acordo com Almeida e Rondon Neto (2010b), os órgãos competentes e até mesmo os próprios moradores devem destinar tempo e dinheiro para manter as árvores sem prejudicar a fiação elétrica das ruas.

O cultivo desta espécie na arborização urbana de Santarém apresenta um importante problema: os indivíduos foram implantados sem análise do lugar de estabelecimento das plantas, o que causa uma disposição desordenada, podendo a copa das árvores danificar a rede de energia elétrica e as raízes com a rede de esgoto. Essas situações levam os moradores a realizar podas drásticas, o que pode ocasionar, muitas das vezes, a um processo de decadência do indivíduo até sua senescência.

A ausência da existência de um Plano de Arborização do município ou previsão deste no Plano Diretor (Lei Municipal no 18.051, de 29 de dezembro de 2006) da cidade pode provocar significativas alterações na arborização urbana desta cidade.

As observações sobre condições fitossanitárias mostram que os insetos $(85,7 \%)$, principalmente formigas, são os principais causadores de injúrias nas plantas. Não foi identificado nenhum caso de vandalismo ou lesão grave nas árvores, apenas lesões leves, tais como pequenos pedaços de casca retirados $(4,1 \%)$. 
Em relação ao estado geral dos indivíduos arbóreos de nim, 55\% encontram-se em ótimo estado, com crescimento livre e bom desenvolvimento da copa, sem lesões graves ou interferências antrópicas. Em estado regular, foram diagnosticados apenas 10\% dos indivíduos, os quais se apresentaram com tronco danificado, poda drástica, entre outras injúrias. Em estado péssimo não foi identificado nenhum indivíduo e nem mortos.

Ademais, concorda-se com Gomes et al. (2016) ao recomendarem o controle de cupins, formigas e microrganismo, visando-se evitar a morte, queda de galhos e até mesmo um indivíduo inteiro, que podem ocasionar riscos de acidentes à população e mesmo para manutenção de uma vegetação sadia e seus atributos paisagísticos.

A vegetação no meio urbano desempenha funções essenciais, sendo fundamental que os indivíduos vegetais sejam mantidos com boa qualidade ambiental no meio urbano, livres de injúrias, para que continuem a proporcionar todos os benefícios que são capazes de gerar ao ambiente e ao homem (NÓBREGA et al., 2014).

Com relação à azaractina, obtida a partir da espécie $A$. indica, é quimicamente interessante, dada sua estrutura complexa (MORGAN, 2009). Este autor destaca que seus frutos são de sabor amargo e não comestíveis e que não são tóxicos aos vertebrados. Alves (2010) recomenda a necessidade de estudos que avaliem níveis seguros de utilização desta espécie, visto que tanto o néctar como o pólen se mostraram tóxicos para Apis melífera, não sendo recomendável o uso do nim indiano como fonte exclusiva de alimento destas abelhas.

\section{CONCLUSÕES}

Os indivíduos da espécie nim indiano apresentaram porte médio, não ocasionando problemas para a fiação elétrica das vias. O tamanho da copa dos indivíduos levantados se mostrou favorável à arborização urbana da cidade.

O cultivo desta espécie exótica apresentou aparente potencial no que se refere ao seu estabelecimento, quando observadas variáveis de crescimento e de resistência à pragas e doenças. Contudo, é de fundamental importância que outras pesquisas se desenvolvam com o objetivo de estudar o uso e o desenvolvimento de espécies nativas na arborização urbana, para que se possa fomentar a adoção de espécies nativas na arborização urbana. 


\section{REFERÊNCIAS}

ALMEIDA, D. N.; RONDON NETO, R. M. Análise da arborização urbana de três cidades da região norte do Estado de Mato Grosso. Acta Amazonica, Manaus, v.40, n. 4, p. 647-656, 2010 a.

ALMEIDA, D. N.; RONDON NETO, R. M. Análise da arborização urbana de duas cidades da região norte do estado de Mato Grosso. Revista Árvore, Viçosa, v. 34, n. 5, p. 899-906, 2010b.

ALVES, J. E. Toxidade do nim (Azadirachta indica A. Juss.: Meliaceae) para Apis melifera e sua importância apícola na caatinga e mata litorânea cearense. $141 \mathrm{f}$. Tese (Doutorado em zootecnia)- Universidade Federal do Ceará, Fortaleza, 2010.

BOTTI, J. M. C.; HOLTZ, A. M.; DE PAULO, H. N.; FRANZIN, M. L.; PRATISSOLI, D.; PIRES, A. A. Controle alternativo do Brevicoryne brassicae (Hemiptera: Aphididae) com extratos de diferentes espécies de plantas. Revista Brasileira de Ciências Agrárias, Recife, v. 10, n. 2, p.178-184, 2015.

BOURSIER, C. M.; BOSCO, D.; COULIBALY, A.; NEGRE, M. Are traditional neem extract preparations as efficient as a commercial formulation of azadirachtin A? Crop Protection, v.30, p.318-322, 2011.

CABRAL, P. I. D. Perícia, Auditoria e Governança Ambiental Arborização Urbana: Problemas e Benefícios. Revista Especialize On-line IPOG, Goiânia, v. 1, n. 6, 2013.

CRISPIM, D. L.; SILVA, M. A.; CHAVES, A. D. C. G.; ALMEIDA, R. R. P.; FREITAS, A. J. F. Diagnóstico da arborização urbana do centro da cidade de Pombal-PB. Revista Verde de Agroecologia e Desenvolvimento Sustentável, Pombal, v. 9, n.1, p.191-196, 2014.

FABRICANTE, J. R.; SANTOS, J. P. B.; ARAÚJO, K. C. T.; COTARELLI, V. M. Utilização de espécies exóticas na arborização e a facilitação para o estabelecimento de casos de invasão biológica. Biotemas, Florianópolis, v. 30, n. 1, p.55-63, 2017.

FILIK, A. V; SILVA, L. F; LIMA, A. M. L. P. Avaliação da arborização de ruas do bairro São Dimas na cidade de Piracicaba/SP através de parâmetros qualitativos. Revista da Sociedade Brasileira de Arborização Urbana, Piracicaba, v. 2, n. 1, 2007.

GOMES, E. M. C.; RODRIGUES, D. M. S.; SANTOS, J. T.; BARBOSA, E. J. Análise qualiquantitativa da arborização de uma praça urbana do Norte do Brasil. Nativa, Sinop, v. 4, n. 3, p.179-186, 2016.

INSTITUTO BRASILEIRO DE GEOGRAFIA E ESTATÍSTICA (IBGE). Cidades: Santarém. 2012. Disponível em: <http://www.ibge.gov.br/cidadesat> Acesso em: 14 mai. 2016.

LIMA, R. M. C.; SILVA JÚNIOR, M. C. Inventário da arborização urbana implantada na década de 60 no Plano Piloto, Brasília, DF. Revista da Sociedade Brasileira de Arborização Urbana, Piracicaba, v. 5, n. 4, p.110-127, 2010.

LUNDGREN, W. J. C.; SILVA, L. F.; ALMEIDA, A. Q. Influência das espécies exóticas arbóreas urbanas na área de cobertura da cidade de Serra Talhada - PE. Revista da Sociedade Brasileira de Arborização Urbana, Piracicaba, v. 8, n. 3, p.96-107, 2013.

MOREIRA, F. T. A.; ARAÚJO, L. C. V.; SILVA, G. H.; ASSIS, M. M.; FERREIRA, A. E. S. Características dendrométricas de um povoamento de nim indiano (Azadirachta indica $\mathrm{A}$. Juss) 
no semiárido paraibano. Revista Verde de Agroecologia e Desenvolvimento Sustentável, Pombal, v. 07, n. 3, p.194-198, 2012.

MORGAN, D. E. Azadirachtin, a scientific gold mine. Bioorganic \& Medicinal Chemistry, v.17, p. 4096-4105, 2009.

NEVES, E. J. M.; REISSMANN, C. B.; DEDECEK, R. A.; CARPANEZZI, A. A. Caracterização nutricional do nim em plantios no Brasil. Revista Brasileira de Engenharia Agrícola e Ambiental, v.17, n.1, p.26-32, 2013.

NÓBREGA, C. C.; SOUTO, P. C.; ARAÚJO, L. H. B.; SILVA, A. C. F.; PINTO, M. G. Análise quanti-qualitativa das espécies arbóreas presentes no Parque Religioso Cruz da Menina, Patos/PB. Enciclopédia Biosfera, Goiânia, v. 10, n. 18, 2014.

PIVETTA, K. F. L; SILVA FILHO, D. F. Arborização Urbana. Boletim Acadêmico - Série Arborização Urbana, Jaboticabal, v. 2, p.37-38, 2002.

RODRIGUES, R. M.; CAVALCANTE, L. F.; SOUTO, A. G. L.; GHEYI, H. R.; MESQUITA, F. O. Growth and regrowth of neem after cutting in saline - sodic soil treated with organic inputs. Revista Caatinga, Mossoró, v. 30, n. 1, p. 116-124, 2017.

SAMPAIO, A. C. F.; ECKER, A. E. A.; MARANGONI, C. J. M.; FIORESE, L. M. R.; SORDI, E. A. Espécies exóticas invasoras na arborização de vias públicas de três bairros de Campo Mourão-PR. Campo Digit@I, Campo Mourão, v.6, n.1, p.31-43, 2011.

SANTOS, R. C.; ANTUNES, L.; BESSEGATTO, D. Espécies exóticas invasoras na arborização urbana de vias públicas de Sananduva/RS. Revista da Sociedade Brasileira de Arborização Urbana, Piracicaba, v. 12, n. 2, p. 39-47, 2017.

SILVA, M. C. A.; ROSA, L. S.; VIEIRA, T. A. Eficiência do nim (Azadirachta indica A. Juss) como barreira natural ao ataque de Hypsipyla grandella (Zeller) (Lepidoptera: Pyralidae) sobre o mogno (Swietenia macrophylla King). Acta Amazonica, v.43, n.1, p.19-24, 2013.

SOTO, J.; DIAZ, J.; RAMIREZ; M. Diagnostico florístico y fitosanitario de las espécies arbóreas presentes en la parroquia Francisco Eugenio Bustamante, Maracaibo, estado Zulia, Venezuela. Revista de la Facultad de Agronomía (LUZ), Maracaibo, v. 31, p.341-361, 2014.

SOUZA, C. S.; DODONOV, P.; CORTEZ, R. B. Diversidade, fitossanidade e adequação da arborização ao ambiente urbano em um bairro na cidade de Ourinhos, SP, Brasil. Revista da Sociedade Brasileira de Arborização Urbana, Piracicaba, v. 7, n. 4, p.77-89, 2012.

VIEIRA, T. A.; ROSA, L. S.; VASCONCELOS, P. C. S.; SANTOS, M. M.; MODESTO, R. S. Sistemas agroflorestais em áreas de agricultores familiares em lgarapé-Açu, Pará: caracterização florística, implantação e manejo. Acta Amazonica, v.37, n.4, p.549-557, 2007. 